\title{
Primary four students' development of reading ability through inquiry-based learning projects
}

\author{
Dr. Kai Wah Samuel Chu, The University of Hong Kong \\ Prof. S.K. Tse, The University of Hong Kong \\ Dr. E. K. Y. Loh, The University of Hong Kong \\ Dr. Ken Chow, Canossa Primary School \\ Mr. Hon-Fai Fung, The University of Hong Kong \\ Ng, Hung Wai Rex, The University of Hong Kong
}

\begin{abstract}
This paper is part of a bigger study that investigates a collaborative instructional approach involving three kinds of teachers (Information Technology, General Studies, and Chinese) and the school librarian in guiding primary 4 (P4) students through two phases of inquiry-based learning (IBL) projects, each lasting for 2-3 months in 20062007.

This collaborative approach in guiding students through the IBL projects has proven to be effective. Not only did the participating students significantly enhance their reading abilities, but they obtained $37.47 \%$ higher grades in their General Studies projects compared with their peers in the previous year (Chu, Chow, Tse, \& Kuhlthau, 2008a).

Using PIRLS, this paper examines the reading tests and surveys completed by the students before and after their IBL projects. Using another perceptual survey, students, teachers and parents' opinions regarding improvement in student reading ability after the completion of the first IBL project was also investigated. This study may shed light on the benefits and possibilities of an integrative instructional approach in improving student reading and language abilities.
\end{abstract}




\section{Introduction}

The effectiveness of inquiry based learning (IBL) has been the subject of numerous studies, and the general acceptance of its value has led the Hong Kong Special Administrative Region (HKSAR) Education Bureau to include IBL in its policy changes for primary education. However, few local schools have successfully integrated an IBL approach within their curricula. In view of this, further studies on implementation of effective IBL approach in local schools and its impact on students are warranted.

This paper is part of a larger study investigating a collaborative instructional approach; four kinds of teaching staff ${ }^{1}$ provided various kinds of support to Primary Four ${ }^{2}$ (P4) students in a local Hong Kong school in the completion of their IBL projects. About 150 students completed two General Studies' group projects, each lasting 2-3 months, from December 2006 to June 2007. The main theme for the first project was "The Earth" and the second "History of Hong Kong and Mainland China". For each theme, students chose their own sub-area to work on.

The teaching staff involved played different roles in guiding students through the projects. The IT teachers helped enhance students' IT literacy (e.g. skills of using Microsoft Excel and PowerPoint), the General Studies teachers focused on teaching research skills (e.g. formulating essential questions and organizing data gathered for the projects), and the Chinese teachers helped students develop the necessary reading and writing abilities for the completion of their projects. Meanwhile, the school librarian assisted in sharpening students' information literacy skills (e.g. doing searches on a news database and in the public library catalog). Figure 1 presents the model of this IBL approach and the various dimensions measured for improvement.

This paper reports on student improvement in reading abilities as a result of the inquiry-based learning projects. Moreover, through working on research topics of their own interest, students are motivated to read more relevant materials. It is therefore suggested that the IBL approach would also bring positive changes to student attitudes towards reading. The possible relationship between reading ability and reading attitude will be examined in the later part of this paper.

\footnotetext{
${ }^{1}$ The school librarian and teachers of General Studies, Chinese and Information Technology.

${ }^{2}$ Primary four in this system is equivalent to the fourth grade in the United States, with students aged nine on average.
} 
Figure 1. The inquiry-based learning model adopted for the General Studies group

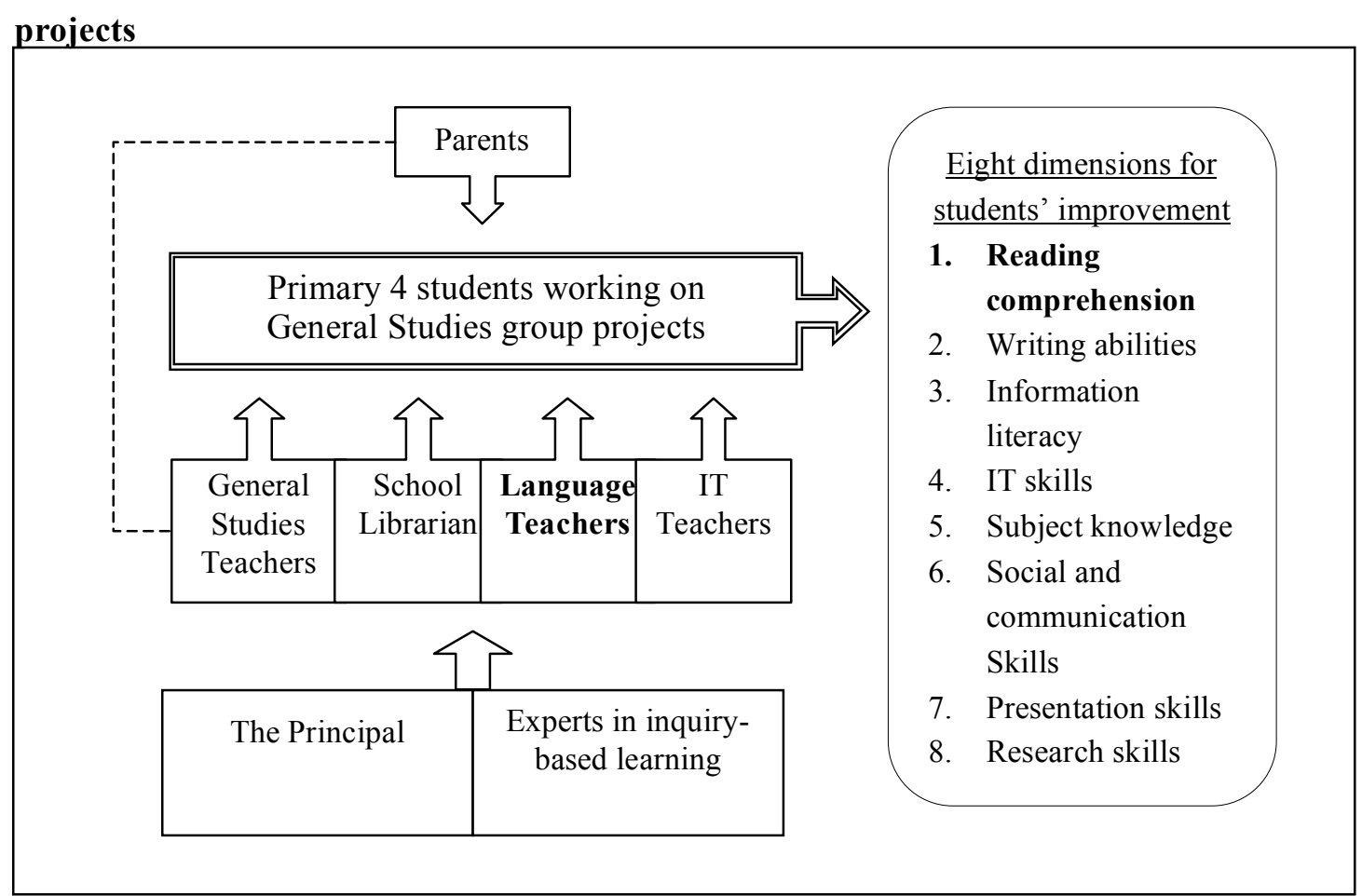

\section{Literature review}

The importance of an IBL approach, as noted by the Education Bureau of the Hong Kong SAR Government (2002), is that it enables students to "develop generic skills and nurture inquiring attitudes or habits of mind that will enable students to continue the quest for knowledge throughout life," and "take a proactive role in the learning process to construct knowledge." In other words, an IBL approach encourages students to focus their study on topics of their own interest and formulation. This is an important characteristic, as research clearly notes that students perform betterwhether in research, subject knowledge or writing-when they are working on subjects that interest them and which they can relate to (Chu, Tang, Chow \& Tse, 2007; Chu, Chow, Tse \& Kuhlthau, 2008a; Frank, Lavy \& Elata, 2003; LaMedica, 1995).

The improvement of reading ability requires the effective mastery of cognitive reading skills and strategies. According to Lau and Chan (2003), students with good reading abilities possess well-developed cognitive skills in reading comprehension. Moreover, proficient readers are better able to apply sophisticated reading strategies, analyze textual organization and possess more metacognitive knowledge in reading 
than less proficient readers (Yau, 2005).

Students with poor language ability however, will find it difficult to develop an intrinsic interest in reading (Lau and Chan, 2003). If students are disinterested in reading, it is more difficult for them to develop their reading ability. Thus, learning environments and curricula should be constructed in a way that will help students build up their reading interest and strategies. IBL is beneficial to students' development in relevant skills in understanding reading materials, such as the process of exploring, selecting, collecting, analyzing, and comprehending information sources (Kuhlthau, 1997). Hence, IBL could be helpful in arousing students' interests in reading and this in turn would enhance their reading abilities.

However, there seems to be a lack of literature that links students' improvement in reading ability to influences from a collaborative IBL approach. This article attempts to fill the gap by relating students', teachers' and parents' perceptions of students' improvement in reading ability to IBL. It also seeks to associate students' improvement in reading ability to the IBL approach adopted in this study.

On the other hand, the IBL approach provides opportunities for students to discuss specific topics to generate more knowledge, as well as stimulating them to read extensively outside the classroom. This is important to the development of students' literacy skills since it encourages and motivates students to read more (McKool, 2007). Hence, the potential influence of IBL approach on students' reading attitude and interests would also be investigated in this study.

\section{Methodology}

The main research questions of this study include:

- What are the key elements of reading ability?

- Is the IBL approach taken in the study effective in helping students achieve a higher level of reading ability?

- Would the IBL approach bring changes to students' attitude towards reading?

\section{Instructional design}

This case study examined about 140 P4 students from a local Hong Kong primary school. The study design involved two phases and students were to complete one IBL project on a topic approved by their General Studies teachers in each phase together with support from their Chinese Language teachers, IT teacher and school librarian.

Students had to decide their research topics according to the theme set for each phase. 
The themes are 'The Earth' and 'History of Hong Kong and Mainland China' respectively. In order to complete the IBL projects, students had to collect materials relating to their own topics. Students were encouraged to explore different sources including books from school and public libraries, newspapers, magazines and online web materials. Students were introduced to the database WiseNews as well.

The focus of this article will be on the assignments created by the Language (Chinese) teachers and the principal investigator of the study, aimed at equipping students with proficient reading skills. In phase 1, a maximum of seven in-class exercises and seven take-home assignments were assigned to the student participants. In phase 2, a maximum of six in-class exercises and seven take-home assignments were assigned. For each in-class exercise, students were required to read an article related to the main theme of the phase and underline the key sentences in the article, followed by writing a summary of the article and their opinions in 100-150 words. For each take-home assignment, students were asked to read at least three pieces of writing (e.g., articles, books) related to the project theme, and then write a research journal entry of 150-200 words about their reading material. The total number of assignments that the researchers were able to collect for this study in phases 1 and 2 are shown in Table 1.

Table 1. In-class exercises and homework collected for each class in the two phases

\begin{tabular}{lllll}
\hline & $\begin{array}{l}\text { In-Class } \\
\text { Exercise } \\
\text { Phase 1 }\end{array}$ & $\begin{array}{l}\text { In-Class } \\
\text { Exercise } \\
\text { Phase 2 }\end{array}$ & $\begin{array}{l}\text { Homework } \\
\text { Phase 1 }\end{array}$ & $\begin{array}{l}\text { Homework } \\
\text { Phase 2 }\end{array}$ \\
\hline Class E $^{3}$ & 37 & 37 & 37 & 35 \\
Class F & 36 & 36 & 36 & 36 \\
Class G & 9 & 8 & 0 & 0 \\
Class H & 25 & 24 & 21 & 25 \\
\hline Total & 107 & 105 & 94 & 96 \\
\hline
\end{tabular}

The school librarian, being the information provider, also played an important role in the development of students' reading ability. Through the school librarian, students could get access to all kind of resources, such as books (e.g. a block loan of 200 books were borrowed from the public libraries), newspaper clips and webpage links, related to the main theme. Besides, the school librarian held training sessions to equip students with the necessary information literacy skills for finding relevant resources from the Web and from the WiseNews database.

\footnotetext{
${ }^{3}$ To protect the privacy of the respondents, the class names have been changed.

${ }^{4}$ Some teachers gave the assignments back to their students at the end of the term and it was difficult to get them back for the study. Hence, assignments available for the study in some classes were lower than other classes.
} 


\section{Evaluation methods}

The students took the reading test from Progress in International Reading Literacy Study (PIRLS) ${ }^{5}$ before and after the completion of the two IBL projects. Their performances before and after working on the two projects would be recorded and compared. Besides, students also filled in the PIRLS's survey on their reading habits, attitudes, and interests. This paper focuses on the changes in students' reading ability. Some discussion would be based on findings from the survey on their reading attitude in the later part of this paper.

The test on students' reading ability focused on two aspects: (i) process of reading comprehension, and (ii) reading and understanding different reading materials. Students are required to employ various reading processes, include focus on specific aspects of text, make simple and more complex inferences, interpret and integrate ideas and information, and examine and evaluate text features. Two types of reading materials were included in the test battery: literary materials such as stories or fables in which pupils read for enjoyment, and informational materials such as scientific descriptions or manuals which pupils had to read for information (Mullis, Kennedy, Martin \& Sainsbury, 2006). Because both types of reading experiences (literary and informational) are important for the reading development of pupils, the reading test battery consisted of one literary passage and one informational passage. Pupils had 40 minutes to answer questions on the first passage, rested for 10 minutes then took another 40 minutes on the second passage of text. Total test scores for each pupil were estimated using the Item Response Theory (IRT) Model (Lord, 1980) based on the responses of each pupil to the test items. The computer program PARSCALE 4 (Muraki \& Bock, 2003) was used in the estimation of the IRT scores of pupils. The IRT scores were scaled to a mean of 500 (Martin, Mullis \& Kennedy, 2003). SPSS was used to conduct parametric tests on the data.

Besides, students, teachers and parents were surveyed with another questionnaire between phase 1 and phase 2 after students had completed their first project. By doing so, the effectiveness of the IBL approach in phase 1 could be evaluated and changes could be made when necessary. This survey would also be a supplement for PIRLS since teachers and parents were not surveyed with PIRLS in this study.

\footnotetext{
${ }^{5}$ PIRLS is a world-wide assessment and research project aims to measure trends in children's reading literacy achievement and collect information on reading-related policy and practices (Mullis, 2008).
} 


\section{Findings and Discussion}

The study collected and analyzed data both quantitatively and qualitatively. The findings of the perceptual survey provided an overview of improvement in students' reading ability from three different perspectives of teachers, parents and students. Key elements of reading ability would be discussed. The results from the PIRLS reading tests were analyzed to examine the students' improvement in reading brought by the IBL approach. The results from the PIRLS survey were also analyzed to examine the effect of IBL approach on students' attitude towards reading and the possible relationship between reading attitude and reading ability.

\section{Teachers, parents and students' opinion on the effectiveness of IBL projects}

Teachers, parents and students themselves, were all of the opinion that there was improvement in students' reading ability via the inquiry-based projects (Figure 2). Teachers saw the most perceived improvement in their students $(3.9 \pm 0.2)$, followed by students themselves $(3.5 \pm 0.2)$. Parents, conversely, perceived the lowest improvement in their children's abilities $(3.3 \pm 0.4)$.

Figure 2. Teachers $(n=10)$, parents $(n=25)$ and students' $(n=132)$ perceptions of reading ability improvement through the inquiry-based projects ${ }^{6}$

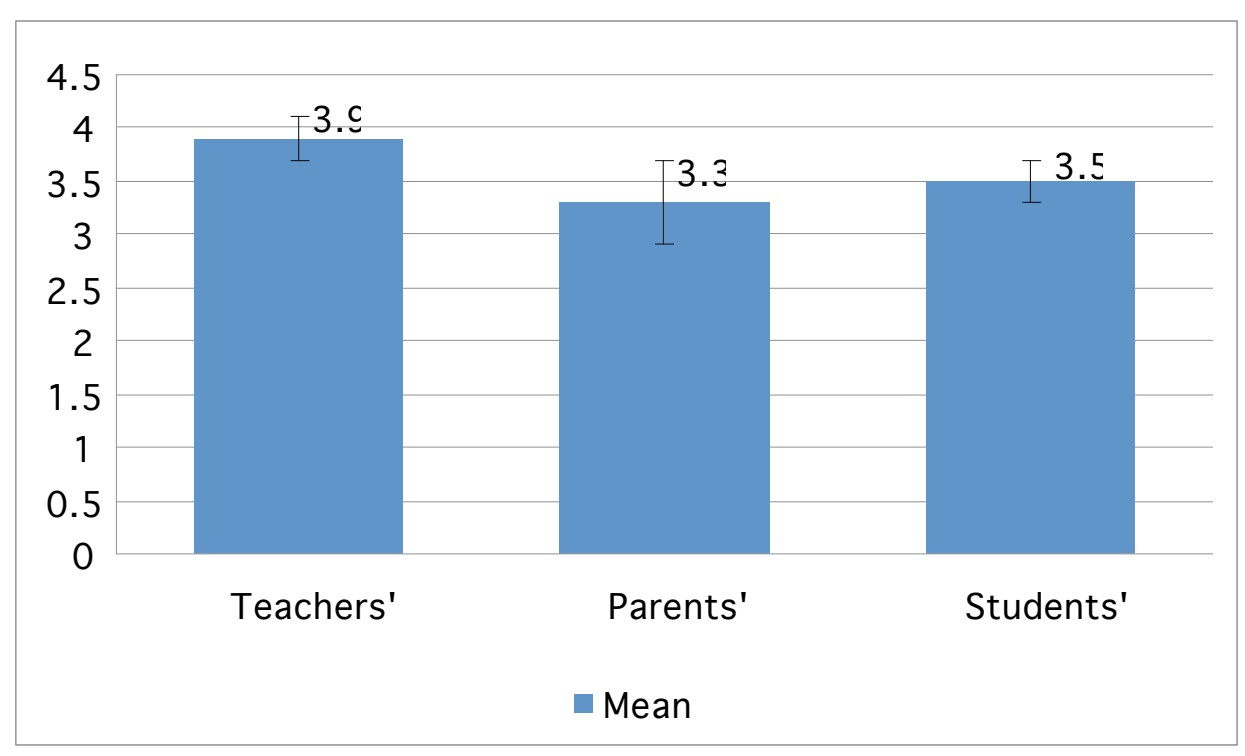

Note: The three parties were answering the question "Did the IBL project help you (the student) improve in reading ability?" according to a scale of 1-5, with 1 as 'not helpful' and 5 as 'most helpful'.

During interviews, parents, teachers and students emphasized progress in three elements of reading ability-better comprehension, faster reading and richer

\footnotetext{
${ }^{6}$ The survey was conducted shortly after the completion of the first IBL project.
} 
vocabulary (Figure 3). This suggests that the assigned exercises for the IBL projects were able to help students improve their reading ability in these three areas.

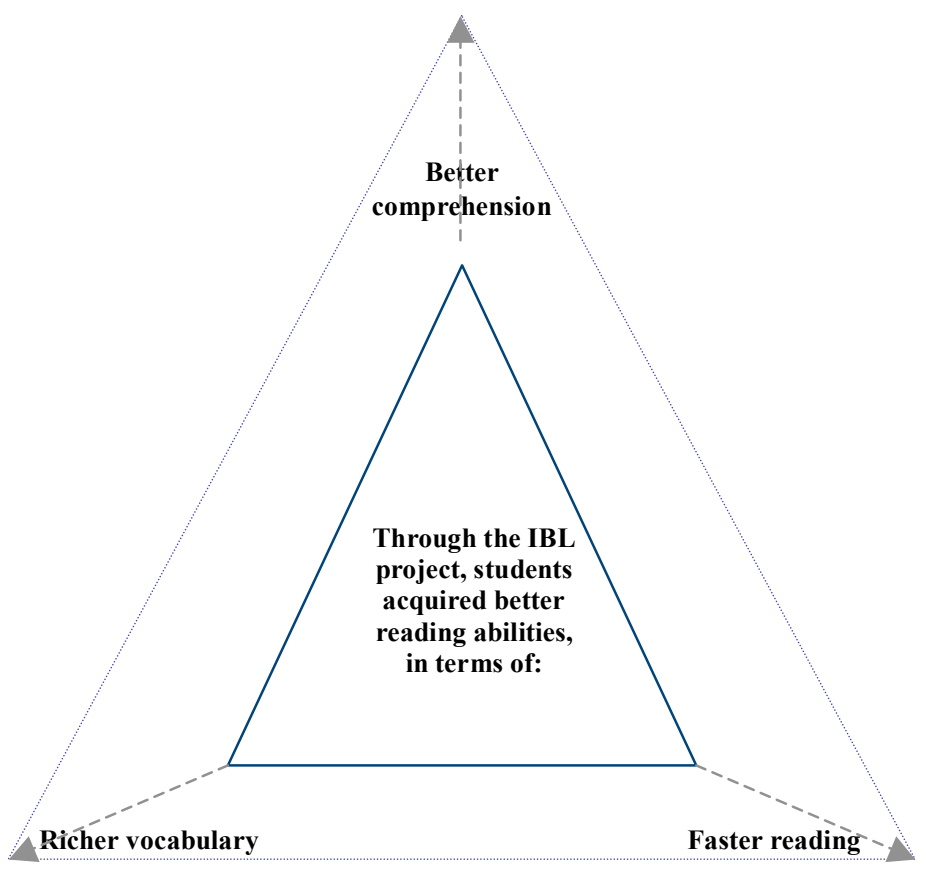

Figure 3. Three key elements of reading ability

In evaluating the perceived improvement in reading ability, one student commented, "We now know how to identify the main ideas of a passage or an article, and know how to select relevant information when much information is given." This reflects their acknowledgement of more advanced comprehension skills through the IBL projects.

A parent expressed perceived improvement in her child's ability to read faster thus: "She was very diligent during the information searching process. Her reading speed and ability to grasp the main points (from articles) have been enhanced too."

Another parent noted his child's gains in vocabulary and language usage through the IBL projects. He said, "My child now knows more vocabulary than before... his skills in using appropriate vocabulary in his writing has also improved."

A teacher commented that "Many (students) said they could read faster than before. Another thing is that students learnt how to figure out the main points (when reading) in Chinese lessons." 
Besides, another teacher noted that "There was an obvious improvement in reading ability in Phase 2. Phase 2's material is more interesting." The IBL projects aroused student' interest in reading and this in turn enhanced their overall reading ability.

\section{Students' performance in PIRLS tests before and after the IBL projects}

As predicted, students' reading performance improved through participation in the IBL projects. Table 2 presents a comparison of the pre-and post-projects PIRLS test performance of the students. The effect sizes reveal that students' improvement in reading ability during the IBL projects period was substantial. Care was taken to ensure an unbiased effect estimate (c.f. Cohen, 1977; Curlette, 1987; Glass et al., 1981; Hattie, 1992; Hedges, 1981). The effect sizes of different parts of the test vary between 0.41 and 0.77 , which imply a medium to large effect (see Table 2). The calculation of effect sizes of different parts of the test employed in the experiment is based on the following formula:

\section{Mean of post-test - mean of pre-test}

SD of pre-test

Table 2. Comparing students' pre-test and post-test reading performance (n of pre-test $=140 ; n$ of post-test $=142$ )

\begin{tabular}{lccccc}
\hline \multirow{2}{*}{ Scores } & \multicolumn{2}{c}{ Pre-test } & \multicolumn{2}{c}{ Post-test } & \multirow{2}{*}{ Effect size } \\
\cline { 2 - 5 } & Mean & S.D. & Mean & S.D. & \\
\hline Overall & 538.53 & 40.18 & 569.64 & 44.96 & 0.77 \\
Literary* & 537.19 & 47.27 & 556.73 & 48.26 & 0.41 \\
Informational** & 540.68 & 42.19 & 562.28 & 42.69 & 0.51 \\
\hline
\end{tabular}

Note: * Reading for enjoyment; ** Reading to acquire and use information (Mullis, Kennedy, Martin \& Sainsbury, 2006). Effect size: $0.2=$ Small, 0.5=Medium, 0.8=Large (Cohen, 1977).

\section{Students' attitude toward reading and their performance in PIRLS tests before and after the IBL projects}

The PIRLS questionnaire investigates students' attitude toward reading (SATR), and their reading self-concept (SRSC). The SATR test asks the students how well they agree with the following statements: (i) I read only if I have to, (ii) I like talking about books with others, (iii) I like people to give me a book as present, (iv) I think reading is boring, (v) I need to read well for my future, and (vi) I enjoy reading ${ }^{7}$. Students responded to the statements on a four-point Likert-scale: (1) disagree a lot, (2)

\footnotetext{
${ }^{7}$ Question i and iv are in reverse coding.
} 
disagree a little, (3) agree a little, and (4) agree a lot. Students' responses to the above statements are then computed as the scale of "Students' Attitudes Toward Reading (SATR)".

As shown in Table 3, the proportion of students in the low, medium and high level of SATR did not change much in the pre-test and post-test. More substantial improvement in overall reading performance were observed in students with medium level (effect size $=0.47$ ) and high level (effect size $=0.48$ ) of SATR than students with low level (effect size $=0.19$ ) of SATR. One interesting finding is that in the pre-test, students with low SATR $(M=543.92)$ outperformed other students with medium $(M=518.77)$ and high SATR $(M=508.05)$ in the reading test. However, in the post-test, students with low SATR $(M=549.76)$ were taken over by other students with medium $(M=570.14)$ and high SATR $(M=571.22)$ in the reading test. This implies that in general, students with more positive attitude towards reading could benefit more from the IBL projects and attain more improvement.

Closer examination on the patterns of student improvement in reading performance shows differences in the two aspects of reading tested by PIRLS (i.e. literacy and informational). For literacy reading performance, students with low SATR did not show any improvement (effect size $=-0.06$ ) while students with medium and high SATR did (effect size $=0.48,0.40$ respectively). This might indicate that the IBL approach, which focuses on informational reading, could also improve literary reading performance in students with medium and high SATR, but is insufficient in improving the literary reading performance of students with low SATR. For information reading performance, it is noteworthy that quite a substantial improvement was also observed in students with low SATR (effect size $=0.32$ ). This indicated that the IBL approach focusing on informational reading is effective in enhancing informational reading performance, even for students with less positive reading attitudes. 
Table 3. Students' attitude toward reading and their performance in PIRLS tests before and after the IBL projects $(\mathrm{N}=150)$

\begin{tabular}{|c|c|c|c|c|c|c|c|}
\hline \multirow{2}{*}{\multicolumn{2}{|c|}{ Scale of SATR }} & \multicolumn{3}{|c|}{ Pre-test reading scores } & \multicolumn{3}{|c|}{ Post-test reading scores } \\
\hline & & \multirow{2}{*}{$\begin{array}{c}\text { Overall } \\
543.92\end{array}$} & \multirow{2}{*}{$\begin{array}{c}\text { Literary } \\
537.80\end{array}$} & \multirow{2}{*}{$\frac{\text { Informational }}{537.17}$} & \multirow{2}{*}{$\begin{array}{l}\text { Overall } \\
549.76\end{array}$} & \multirow{2}{*}{$\frac{\text { Literary }}{535.59}$} & \multirow{2}{*}{$\begin{array}{c}\text { Informational } \\
544.85\end{array}$} \\
\hline Low SATR & Mean & & & & & & \\
\hline & S. D. & 30.54 & 35.53 & 23.88 & 56.95 & 49.36 & 55.15 \\
\hline & $\mathrm{N}$ & 9 & 8 & 8 & 11 & 9 & 9 \\
\hline Effect size & & & & & 0.19 & -0.06 & 0.32 \\
\hline \multirow[t]{3}{*}{ Medium SATR } & Mean & 518.77 & 530.69 & 546.52 & 570.14 & 552.97 & 566.51 \\
\hline & S. D. & 109.66 & 46.16 & 51 & 46.04 & 55.82 & 36.33 \\
\hline & $\mathrm{N}$ & 54 & 51 & 41 & 49 & 49 & 49 \\
\hline Effect size & & & & & 0.47 & 0.48 & 0.39 \\
\hline \multirow[t]{3}{*}{ High SATR } & Mean & 508.05 & 541.60 & 558.55 & 571.22 & 560.90 & 561.50 \\
\hline & S. D. & 132.68 & 48.66 & 119.00 & 43.19 & 43.11 & 44.92 \\
\hline & $\mathrm{N}$ & 87 & 78 & 78 & 83 & 83 & 83 \\
\hline Effect size & & & & & 0.48 & 0.40 & 0.02 \\
\hline \multicolumn{8}{|l|}{ Note: } \\
\hline $\begin{array}{l}\text { - Effect size q } \\
\text { quantify the d }\end{array}$ & d sho & e size of & erence bet & n two groups (Coe, & 02). It wa & sed here to & \\
\hline
\end{tabular}




\section{Perceptions of students' changes in reading interest after phase 1 of the IBL project}

Figure 4. Perceptions of changes in students' reading interest through the IBL approach

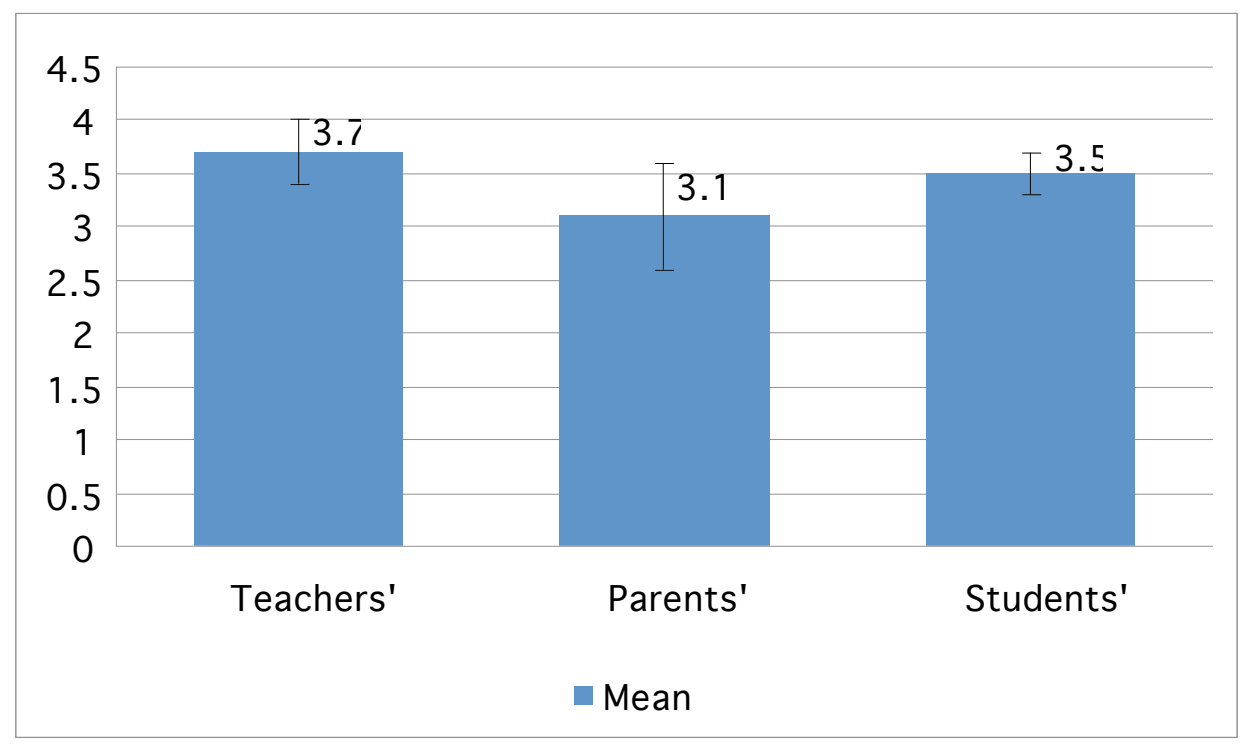

Notes:

- The three parties were answering the question "Did the IBL project help your students, your child or yourself increase your interest in reading?" according to a scale of $1-5$, with 1 as 'none' and 5 as 'a lot'.

- Range of response for teachers $(\mathrm{n}=10): 3.7-4.0$

- Range of response for parents $(\mathrm{n}=25): 3.1-3.5$

- Range of response for students $(\mathrm{n}=135): 3.5-4.0$

As indicated in Figure 4, all three parties have positive perceptions of the changes in students' reading interest through the IBL approach. The mean scores for changes in students' reading interest given by teachers, parents and students are 3.7, 3.1 and 3.5 respectively. The mean score given by teachers was significantly higher than that of parents (by 0.6); teachers generally perceived a greater positive change in their students' reading interest. One possible reason for parents giving the lowest mean score may be that some of them considered their children to have had a high level of interest in reading even before the IBL projects. Moreover, the score given by teachers was even greater than that given by the students themselves. 


\section{Perceptions of students' changes in reading interest before and after the 2 phases of the IBL project}

The PIRLS reading habit and attitude survey was conducted before and after the two phases of the IBL projects. The results reveal that $12.9 \%$ of students $(n=132)$ experienced an increase in reading interest after completing both IBL projects. However, $25 \%$ of students experienced a decrease in their reading interest (Table 4). In other words, although the perceptions of students' reading interest under the IBL approach was generally positive between the two phases, many students had a lower reading interest towards the end. Some teachers gave account for this by the fact that students started to lose interest in doing a similar project in the second phrase, even though they showed interest the first time around; a loss of interest in the project could mean a loss of interest in reading as well. This observation is similar to the change in students' writing ability before and after the IBL projects, which has been published in another paper. Students in all four classes improved in their writing ability after the first phase, but three out of four classes showed a decline at the end of the second phase (Chu, Chow, Yim, Chow, Ha, \& Fung, 2007). The results suggest that it is important not to overload students with similar projects over a long period of time since it could lead to a loss of students' interest in the projects and the related readings.

Table 4. Changes in students' reading interest under the IBL approach

\begin{tabular}{lccc}
\hline & Frequency (n) & Valid Percent (\%) & Cumulative Percent (\%) \\
\hline Increase & 17 & 12.9 & 12.9 \\
No Change & 82 & 62.1 & 75.0 \\
Decrease & 33 & 25.0 & 100.0 \\
\hline Total & 132 & 100.0 & \\
\hline
\end{tabular}

Note: Students were asked to respond to the statement "I enjoy reading". Students answered with a scale of $1-4$, with 1 as 'strongly disagree' and 4 as 'strongly agree'. A change in rating of 1 or more is regarded as a change of increase/decrease in here. 


\section{Correlation between students' reading ability and their reading interests}

Students' responses to two statements of the PIRLS survey were further analyzed. The first one was "I enjoy reading" which revealed students' interest in reading. The second one was "Reading is easy" which indicated their self-perceived reading ability. To examine if the confidence in their own reading ability correlated with their reading interests, Spearman's correlation coefficients were computed. The results are shown in Table 5.

Table 5. Correlation coefficients between students' reading ability and their reading interests, before and after the entire IBL project ${ }^{\text {a* }}$

\begin{tabular}{lcc}
\hline & \multicolumn{2}{c}{ I enjoy reading } \\
\cline { 2 - 3 } & Pre-test & Post-test \\
\hline${ }^{\wedge}$ Reading is easy & $0.41^{* *}$ & $0.29^{* *}$
\end{tabular}

Notes:

* Spearman correlation is used for generating the above correlation coefficients

* Valid pair-wise sampling size ranges from 133 to 136.

$\wedge$ Questions were set according to a scale of 1-4, with 1 as 'strongly disagree' and 4 as 'strongly agree'

** Correlation is significant at the 0.01 level (2-tailed).

The statistically significant correlation coefficient indicates a positive correlation between students' self-perceived reading ability and their interest in reading. This shows that in general, students who consider reading as an easy task would tend to be more interested in reading. This reflects that the students' self-perceived reading ability and reading interest are positively correlated. The IBL projects could help students to improve their reading ability by arousing interests in reading. Through working on topics of interest, students are motivated to read more and their interests and abilities in reading would be enhanced through the completion of the projects.

\section{Conclusion and implications}

This paper demonstrates that the IBL approach involving support for students from four kinds of teaching staff proves to be effective in helping students improve their reading ability. Besides, the study demonstrates that the IBL approach was successful in altering students' attitude towards reading, particularly in raising their interest in reading. This in turn correlates with their improvement in reading. After all, this approach led to an improvement in the overall quality of students' group projects when compared to students in the previous year. However, it is noteworthy that overloading upper primary students with similar projects might lead to a loss of interest, limiting the benefits of the IBL approach. Hence, maintenance of students' 
interest in the projects should be taken into consideration when designing an IBL curriculum. It is hoped that the findings and results from this paper will help provide deeper insights into the possibility of implementing the proposed inquiry-based learning approach in primary education curricula.

\section{Limitations and future studies}

In this study, students were tested and surveyed at the beginning before they started to work on their projects and at the very end after completing both projects. However, as mentioned earlier, interests in the projects could be lost due to overloading of two similar projects in upper primary students and this might influence students' performance in the test. In future studies, it would be desirable to test students' reading ability right after the completion of one long enough IBL project.

Besides, difficulties existed in collecting assignments from students for this study. For example, referring back to Table 1, very limited data was collected from Class G. The reason behind was that the assignments were given back to the students at the end of the term and it was difficult to recollect them. If future studies are to be done, it is important to ensure that students' assignments are collected for research purpose before they are given back to the students.

\section{Acknowledgements}

We would like to thank Ms. Lisa Ma Duan Yang, Ms. Ellen Cheung, and Ms. Jenny $\mathrm{Ng}$ for their contributions in this project. 


\section{References:}

Centre of Inquiry-Based Learning, Duke University. (2000) What Do We Mean by Inquiry? (Retrieved December 28, 2007 from http://www.biology.duke.edu/cibl/inquiry/what_is_inquiry.htm)

Chu, S., Chow, K., Tse, S.K. \& Kuhlthau, C.C, (2008a). Grade Four Students' Development of Research Skills through Inquiry-based Learning Projects. School Libraries Worldwide.

Chu, S., Chow, K., Tse, S.K. \& Kuhlthau, C.C, (2008b). Inquiry-based learning with a partnership of three types of teachers and the school librarian. (Working paper)

Chu, S., Tang, Q, Chow, K. \& Tse, S.K. (2007). A study on inquiry-based learning in a primary school through librarian-teacher partnerships. The 2007 IASL Conference, National Taiwan Normal University, Taipei, Taiwan, 16-20 July 2007.

Coe, R. (2002). It's effect size, stupid: What effect size is and why it is important. The British Educational Research Association annual conference, Exeter, 12-14 September, 2002.

Cohen, J. (1977). Statistical Power Analysis for the Behavioral Sciences (Rev. ed.). New York: Academic Press.

Curlette, W.L. (1987). The meta-analysis effect size calculator: A basic program for reconstructing unbiased effect sizes. Educational and Psychological Measurement 47: 107-109.

Education Bureau, the Government of the Hong Kong Special Administrative Region (2002). General Studies for Primary Schools Curriculum Guide. (Retrieved on December 28, 2007 from http://cd.edb.gov.hk/kla_guide/GS_HTML/english/ch4/ch42.html)

Frank, M., Lavy, I., \& Elata, D. (2003). Implementing the project-based learning approach in an academic engineering course. International Journal of Technology and Design Education, (13), 273-288.

Glass, G.V., McGaw, B. \& Smith, M.L. (1981). Meta-analysis in Social Research. 
Beverly Hills: Sage.

Hattie, J. (1992). Measuring the effects of schooling. Australian Journal of Education 30: 5-13.

Hedges, L.V. (1981). Distribution theory for Glass's estimator of effect size and related estimators. Journal of Educational Statistics 6: 107-128.

Kuhlthau, C. C. (1997). Learning in Digital Libraries: An Information Search Process Approach. Library Trends, 45 (4), 708-724.

LaMedica, M. (1995). How To Encourage the Writing Process in Primary Grades. New Paltz, NY: Research Project, State University of New York at New Paltz (ERIC Document Reproduction Service No. ED 379677), 1-38.

Lau, K. L. \& Chan, D. W. (2003). Reading Strategy Use and Motivation Among Chinese Good and Poor Readers in Hong Kong. Journal of Research in Reading, 26 (2), 177-190.

Lord, F. M. (1980). Applications of item response theory to practical testing problems. Mahwah, NJ: Erlbaum.

Martin, M. O., Mullis, I. V. S., \& Kennedy, A. M. (Eds.). (2003). PIRLS 2001 technical report. Chestnut Hill, MA: Boston College.

McKool, S. S. (2007). Factors that influence the decision to read: An investigation of fifth grade students' out-of school reading habits. ProQuest Education Journals, 44, 111-131.

Mullis, I. V. S., Kennedy, A. M., Martin, M. O., Sainsbury, M. (2006). PIRLS: Assessment Framework and Specifications. Progress in International Reading Literacy Study ( $2^{\text {nd }}$ Edition). International Association for the Evaluation of Educational Achievement.

Muraki, E., \& Bock, D. (2003). PARSCALE 4. Lincolnwood, IL: SSI.

Stahl, S. A. \& Yaden, D. B. Jr. (2004). The Development of Literacy in Preschool and Primary Grades: Work by the Center for the Improvement of Early Reading Achievement. The Elementary School Journal, 105 (2), 141-165. 